\title{
Responses of dynamic proteome changes in Zizania latifolia to fresh-cut operation during room temperature $\left(25^{\circ} \mathrm{C}\right)$ storage
}

\begin{abstract}
In order to explore the molecular mechanism of fresh-cut operation accelerating senescence and quality deterioration of $Z$. latifolia, the response of dynamic proteome change in $Z$. latifolia to fresh-cut operation during room temperature $\left(25^{\circ} \mathrm{C}\right)$ storage was studied. 35 protein spots were identified to change significantly $(\mathrm{p}<0.05)$ from the total 660 protein spots on the gels by MALDI-TOF/TOF. Compared with the control, 29 proteins showed similar expression pattern after fresh-cut operations in spite of the difference in abundance between two treatments. Meanwhile, six spots (plant basic secretory protein, adenosine kinase, C2 domain, class III peroxidases, LbH_gamma_CA_like, small Ras-related GTPbinding protein), which were down-regulated in whole $Z$. latifolia, increased after freshcut operation during storage. Fresh-cut operations that accelerate senescence and quality deterioration of $Z$. latifolia might be due to the production and transduction of wounding signals, acceleration of carbohydrate and nucleotide catabolism, disorder of energy homeostasis, enhancement of free radical damage, as well as degradation of cell structure.
\end{abstract}

Volume 5 Issue 2 - 2017

\author{
Haibo Luo, ${ }^{1,2}$ Libin Wang, ${ }^{2}$ Li Jiang, ${ }^{2}$ Weihua \\ Wang, ${ }^{2}$ Zhifang $\mathrm{Yu}^{2}$ \\ 'Department of Food Science, Zhejiang Pharmaceutical College, \\ China \\ ${ }^{2}$ College of Food Science and Technology, Nanjing Agricultural \\ University, China
}

\begin{abstract}
Correspondence: Zhifang Yu, College of Food Science and Technology, Nanjing Agricultural University, Nanjing, 210095 , P.R. China, Tel +86 2584399098 , Fax +86 2584395618 ,
\end{abstract} Email yuzhifang@njau.edu.cn

Received: January 12, 2017 | Published: March 07, 2017

Keywords: zizania latifolia, fresh-cut, senescence, quality deterioration, proteomics

\section{Introduction}

Zizania latifolia (Griseb.) Turcz. ex Stapf, botanically different from the three species (Z. aquatica, Z. palustris and Z. texana) grown in North America, is a perennial aquatic grass belonging to tribe Oryzeae of the grass family (Poaceae) in China. ${ }^{1}$ Z. latifolia grows along the littorals of freshwater lakes, streams, marshes and pools. ${ }^{2}$ It is usually parasitized by the smut fungus (Ustilago esculenta P. henn.), which stimulates enlargement of the culms of the grass. ${ }^{3,4}$ The enlarged infected culms have been eaten as a vegetable in China since the 10th century, commonly called Jiaobai, Jiaosun, Gusun, Gushou or Gaosun. ${ }^{5}$ Because of its highly nutritional and economic value, the vegetable has been widely cultivated in rice fields of south China.

Z. latifolia is very suitable to be processed into fresh-cut product. It is usually cut into a cube, slice or shred before marketing. ${ }^{6}$ However, fresh-cut operations may accelerate the senescence and quality deterioration triggering cut surface browning, tissue lignification, shriveling, microbial contamination, off-flavor, respiratory rate, cellulose and lignin contents increase, which reduced the shelf life of fresh-cut Z. latifolia to 2-3days at room temperature. ${ }^{6}$ Therefore, clarification of the mechanisms involved in senescence and quality deterioration is of great importance to extend the shelf life of freshcut products. Previously, the physiological and biochemical responses in Z. latifolia after fresh-cut operation have been investigated., In general, fresh-cut processing operations destroys the integrity of Z. latifolia, which in turn promotes a faster physiological deterioration and biochemical changes such as respiratory activity, ethylene production, reactive oxygen species and malondialdehyde accumulation, lignification and antioxidant-related enzymes changes etc., thus accelerate the rate of senescence and quality deterioration. ${ }^{7}$ Nevertheless, these researches are mainly focused on wounding stress-induced changes at physiological and biochemical levels. ${ }^{9}$

Fresh-cut products, which are subjected to mechanical damage by cutting operations, are still living organisms. Proteins play crucial roles in the structure and function of all living cells and together with nucleic acids, carbohydrates and lipids, form the biochemical basis of life. ${ }^{10,11}$ Currently, proteomic approaches are being extensively used in fruits and vegetables to gain understanding on the mechanisms related to ripening and regulation, ${ }^{12}$ senescence, ${ }^{13}$ stress response ${ }^{14}$ and preservation. ${ }^{15,16}$ Luo et al., ${ }^{13}$ analyzed the protein profile in Z. latifolia during storage at $1^{\circ} \mathrm{C}$ and found that the senescence of postharvest $Z$. latifolia may be a consequence of multiple reasons, comprising the regulation of material metabolism, change of energy metabolism pathway, decline of reactive oxygen scavenging capacity and degradation of cell structure. In addition, we analyzed the changes in the protein profile of $Z$. latifolia during refrigerated $\left(1^{\circ} \mathrm{C}\right)$ storage. Results showed that 25 proteins differentially expressed and identified, with their functions mainly concentrated on cell structure, stress response and defense, and senescence. ${ }^{14}$ However, the molecular mechanism of senescence and quality deterioration in fresh-cut Z. latifolia is still not well understood. Also, there is limited information available on the wounding-responsive proteins occurring in the vegetable tissues after fresh-cut operation during storage at room temperature.

The objective of this study was to determine the response of dynamic proteome change in Z. latifolia to fresh-cut operation during room temperature $\left(25^{\circ} \mathrm{C}\right)$ storage. We hope our result would explore the molecular mechanism of fresh-cut operation accelerating the senescence and quality deterioration of $Z$. latifolia.

\section{Materials and methods}

\section{Plant material}

Fresh Z. latifolia at mature stage were hand-harvested from a commercial farmland in Yixing, Jiangsu, China. $18 \mathrm{Kg}$ Z. latifolia with uniform size and invisible defects, were selected, rinsed with tap water, and then randomly divided into two groups. The first group was manually peeled and cut into slices of $3 \sim 5 \mathrm{~mm}$ thickness with a sharp 
stainless steel knife, and the second group (whole stem) acted as the control. The slices and the whole stem (control) were then packaged into polyethylene plastic bags (thickness: $15 \mu \mathrm{m}$, size: $40 \mathrm{~cm} \times 60 \mathrm{~cm}$ ) before storage at $25^{\circ} \mathrm{C}$. Samples $(3 \mathrm{Kg})$ were taken after 0,3 and 5 days, respectively, frozen in liquid nitrogen, and then stored at $-20^{\circ} \mathrm{C}$ until further analysis.

\section{Protein extraction and two-dimensional electrophoresis}

Protein extraction was carried out according to the method of Liu et al., ${ }^{7} 10 \mathrm{~g}$ sample ground into powder in liquid nitrogen was homogenized with $15 \mathrm{ml}$ of ice-cold solubilisation buffer $(\mathrm{pH} 8.3$ ) consisting of $1 \mathrm{mmolL}^{-1}$ PMSF, $60 \mathrm{mmolL}^{-1}$ Tris, $1.05 \mathrm{molL}^{-1}$ sucrose, $10 \mathrm{mmolL}^{-1}$ EGTA, $1 \%$ Triton X-100 and $1 \mathrm{mmolL}^{-1}$ DTT. After centrifugation at $16,000 \times \mathrm{g}$ for $30 \mathrm{~min}$ at $4^{\circ} \mathrm{C}$, the supernatant was collected and immediately mixed with three volumes of ice-cold Trissaturated phenol $(\mathrm{pH} 7.8)$ followed by incubation at $4^{\circ} \mathrm{C}$ for at least $2 \mathrm{~h}$ and centrifugation at $16,000 \times \mathrm{g}$ for $30 \mathrm{~min}$. The upper phenolic phase was collected and precipitated overnight with five volumes of chilled acetone at $-20^{\circ} \mathrm{C}$ prior to centrifugation at $16000 \times \mathrm{g}$ for $30 \mathrm{~min}$ at $4^{\circ} \mathrm{C}$ and rinsed twice with ice-cold methanol and acetone. The pellets were air dried at room temperature and dissolved overnight at $4^{\circ} \mathrm{C}$ with lysis buffer $\left(7 \mathrm{molL}^{-1}\right.$ urea, $2 \mathrm{molL}^{-1}$ thiourea, $4 \%$ (w/v) CHAPS, $1 \%$ $(\mathrm{w} / \mathrm{v})$ DTT and $0.5 \%(\mathrm{v} / \mathrm{v}) \mathrm{pH} 4-7$ IPG buffer). Protein concentrations were determined using Coomassie brilliant blue (CBB) G250 staining method, and samples were stored at $-20^{\circ} \mathrm{C}$ until two-dimensional electrophoresis (2-DE). ${ }^{14}$

\section{2-DE}

$1 \mathrm{mg}$ protein samples were diluted in a final volume of $350 \mu \mathrm{L}$ and loaded onto $17 \mathrm{~cm} \mathrm{pH} \mathrm{4-7} \mathrm{immobilized} \mathrm{pH}$ gradient (IPG) strips (Bio-Rad). The running conditions were as follows: $50 \mathrm{~V}$ for $12 \mathrm{~h}$ (rehydration), $100 \mathrm{~V}$ in slow for $1 \mathrm{~h}, 200 \mathrm{~V}$ in slow for $1 \mathrm{~h}, 500 \mathrm{~V}$ in slow for $1 \mathrm{~h}, 1000 \mathrm{~V}$ in slow for $1 \mathrm{~h}, 4000 \mathrm{~V}$ in linear for $2 \mathrm{~h}, 8000 \mathrm{~V}$ in linear for $2 \mathrm{~h}$ and then run at $8000 \mathrm{~V}$ for $7.5 \mathrm{~h}$. The strips were equilibrated for $15 \mathrm{~min}$ in $2 \%(\mathrm{w} / \mathrm{v})$ DTT with equilibration buffer $\left(50 \mathrm{mmolL}^{-1}\right.$ Tris$\mathrm{HCl} \mathrm{pH} \mathrm{8.8,} 6 \mathrm{molL}^{-1}$ urea, 20\% (v/v) glycerol and 2\% (w/v) SDS) followed by $15 \mathrm{~min}$ in $2.5 \%(\mathrm{w} / \mathrm{v})$ iodoacetamide in equilibration buffer. For the second dimension, the focused strips were loaded and run on SDS-PAGE 12\% polyacrylamide gels using the Ettan Six vertical set (GE Healthcare) for $1.5 \mathrm{~h}$ at $1 \mathrm{~W} / \mathrm{gel}$, followed by $15 \mathrm{~W} /$ gel during $4 \mathrm{~h}$. After SDS-PAGE, gels were stained with $0.12 \% \mathrm{CBB}$ G250. Three biological replicates were performed for each storage time

\section{Image analysis}

The gels were scanned using a Versdoc 3000 scanner (Bio-Rad) at $300 \mathrm{dpi}$ and saved as the GSC image files. Image analysis of each gel was performed using the PDQuest 2-DE analysis software Version 8.0.1 (Bio-Rad).

\section{Tryptic digestion of spots}

Spots showing changes statistically significant $($ at $p<0.05)$ and above a 2-fold threshold were carefully excised from the gels. The protein spots digestion with trypsin was performed according to the method described by Luo et al. ${ }^{14}$

\section{Identification of proteins by MALDI-TOF/TOF and database search}

Protein identification was performed by Shanghai Bo-Yuan Biological Technology Co., LTD, Shanghai, China. Database search were performed using GPS Explorert ${ }^{\mathrm{TM}}$ software v3.6 (Applied Biosystems, USA) over National Center for Biotechnology Information nonredundant database using the MASCOT 2.1 (Matrix Science Ltd., London). The database search was restricted to green plants. The functional classification of the identified proteins was annotated using the database at http://uniprot.org/uniprot. For protein accessions identified by MASCOT that had no functional annotation, a function was assigned via BLASTP searches of the corresponding protein accessions.

\section{Results}

\section{2-DE analysis of whole and fresh-cut Z. latifolia during storage at $25^{\circ} \mathrm{C}$}

During storage, the symptoms of senescence and quality deterioration in both whole and fresh-cut $Z$. latifolia are gradually severe including shell etiolation, surface browning, and tissue hollowness in whole Z. latifolia as well as cutting surface browning, and tissue lignification in fresh-cut $Z$. latifolia (Figure 1). The proteins from whole and fresh-cut $Z$. latifolia during storage were extracted and separated by 2-DE. The 2-DE maps were obtained using isoelectric focusing (IEF) on $17 \mathrm{~cm} \mathrm{pH} \mathrm{4-7} \mathrm{IPG} \mathrm{gels} \mathrm{(Bio-}$ Rad) followed by SDS-PAGE on $12 \%$ polyacrylamide gels before staining with Coomassie brilliant blue G250 (Figure 2). The 2-DE gels were matched and analyzed by PDQuest 2-DE analysis software Version 8.0.1. Approximately 660 protein spots were detected on the gels. Quantitative image analysis of three replicates of each sample revealed that 39 protein spots showed a more than 2.0-fold increase/ decrease in protein abundance with $\mathrm{p}<0.05$ in at least one storage time point compared to the whole $Z$. latifolia of corresponding time point. The specific distribution in Figure 3 and the magnified views of some differentially expressed proteins were shows in Figure 4.
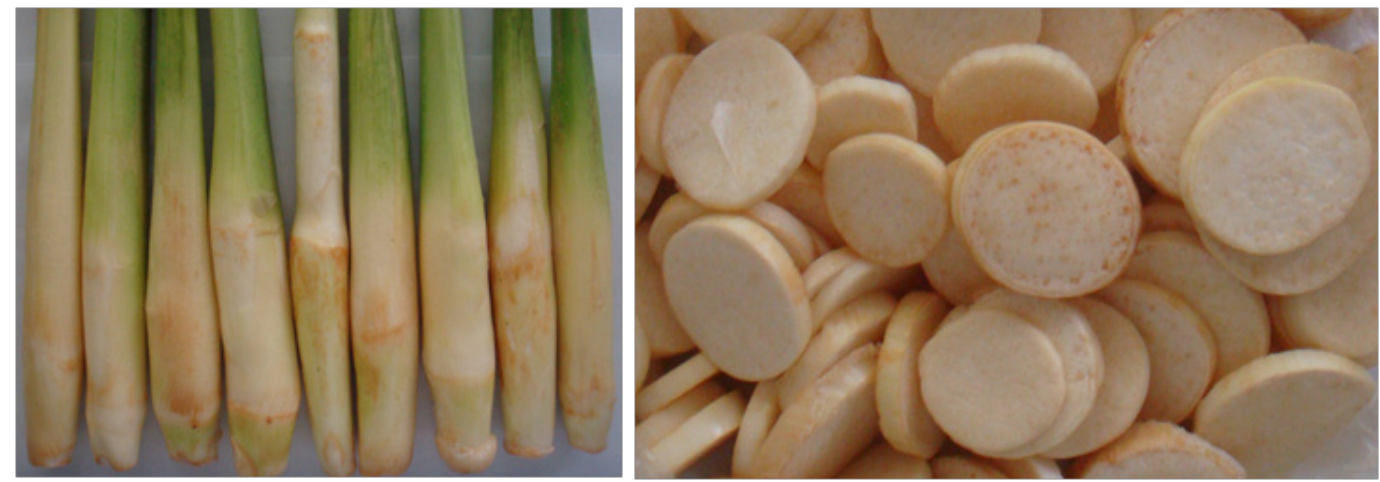

Figure I Representatives of whole and fresh-cut Z. latifolia after 3 days of storage at $25^{\circ} \mathrm{C}$. 

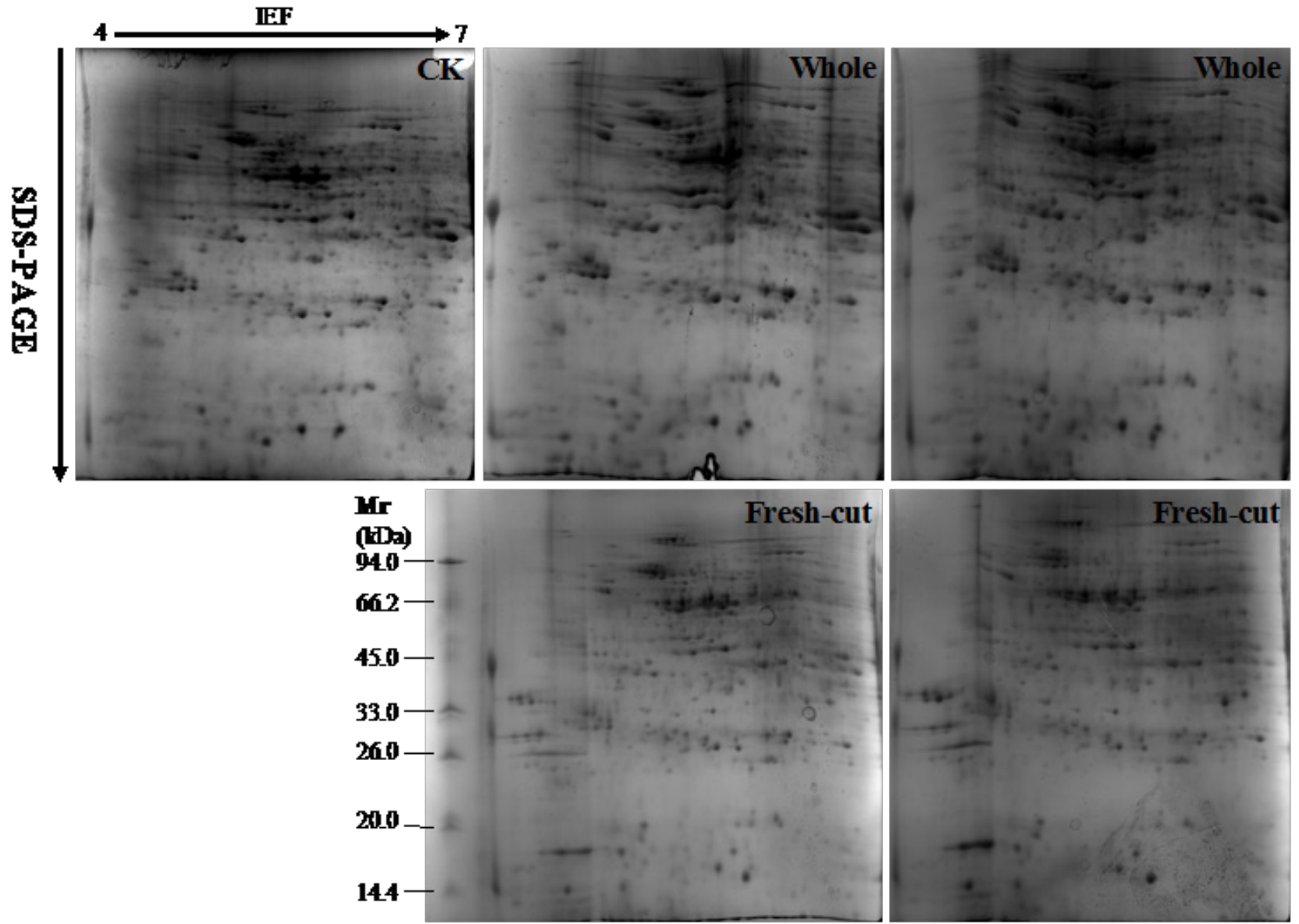

0 d

$3 \mathbf{d}$

$5 \mathbf{d}$

Figure 2 Representative 2-DE gels from whole and fresh-cut Z. latifolia during storage at $25^{\circ} \mathrm{C} .0 \mathrm{~d}$ was used to build the master gel by matching the 2-DE images of different storage time ( 3 and 5 d). Proteins ( $I \mathrm{mg}$ ) were separated on a $17 \mathrm{~cm} \mathrm{IPG} \mathrm{strips} \mathrm{(pH} \mathrm{4-7)} \mathrm{and} \mathrm{subsequently} \mathrm{on} \mathrm{a} \mathrm{I2 \%} \mathrm{SDS-PAGE} \mathrm{gel.The} \mathrm{spots}$ were visualized by $C C B \mathrm{G} 250$ staining.

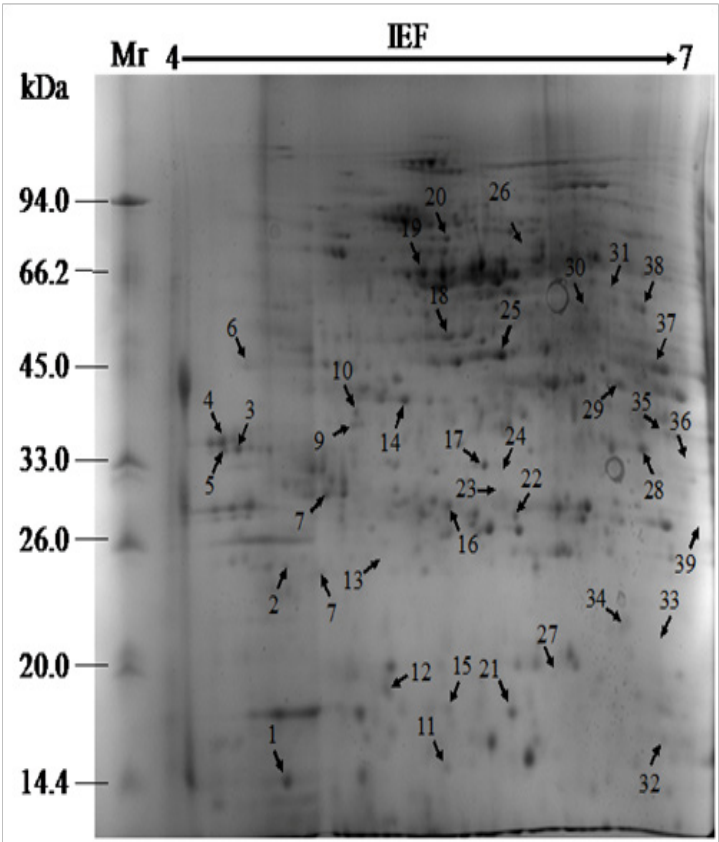

Figure 3 2-DE reference map of Z. latifolia.All differentially expressed proteins are numbered and indicated by arrows.

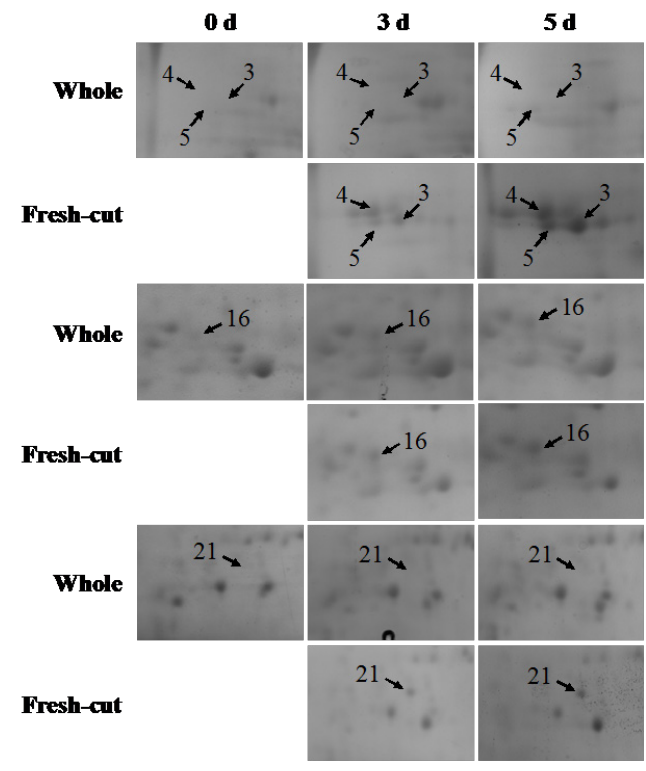

Figure 4 Magnified views of some differentially abundant proteins marked in Figure 2.

Different storage times were showed on the top. Arrows and numbers are indicating the differential spots among different storage time. 


\section{Identification by mass spectrometry and functional analysis of differentially expressed proteins}

35 out of 39 spots which significantly changes $(p<0.05)$, were successfully identified and could then be classified into seven functional categories as listed in Figure 5, including signal transduction (8.6\%), metabolism $(22.9 \%)$, cell structure $(8.6 \%)$, stress response and defense $(31.4 \%)$, protein synthesis $(11.4 \%)$, senescence $(5.7 \%)$, and unclear functional proteins (11.4\%). Cluster analysis was carried out on differentially expressed proteins from day 0 to day 5 (Figure 6), revealing a dynamic proteome profile shift of $Z$. latifolia at different time points during storage at $25^{\circ} \mathrm{C}$.

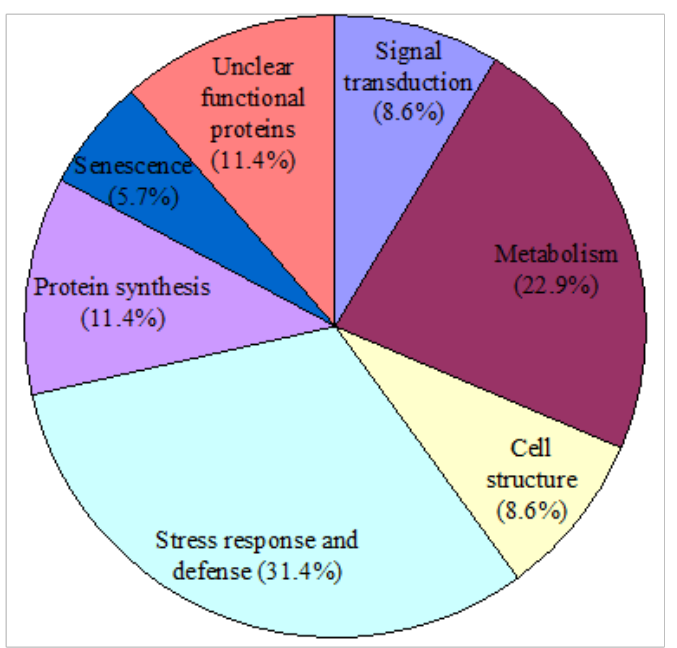

Figure $\mathbf{5}$ The functional distribution of identified proteins expressed differentially covering seven protein groups categorized according to their putative functions.

The numbers and percentages of each protein group are indicated.

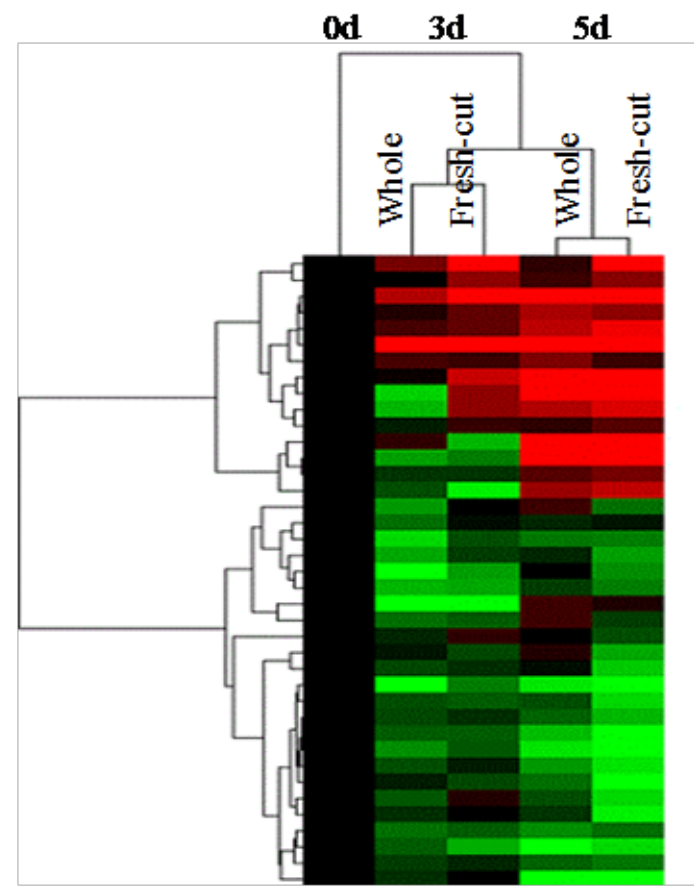

Figure 6 Cluster analysis of whole and fresh-cut Z. latifolia during storage at $25^{\circ} \mathrm{C}$.
As shown in Table 1, 14 out of the 35 differentially expressed and identified proteins were up-regulated while the other were downregulated during the storage of whole $Z$. latifolia. For the up-regulated proteins, spot 14 (fructokinases), spot 17 (glycosyl hydrolases family 17), spot 19 (2,3-bisphosphoglycerate-independent phosphoglycerate mutase) and spot 26 (diphosphonucleotide phosphatase 1) were related to metabolism; spot 1 (profilin) to cell structure; spot 3 (beta1,3-glucanase precursor), spot 4 (glucan endo-1,3-beta-glucosidase), spot 5 (beta-1,3-glucanase precursor), spot 12 (universal stress protein family), spot 21 (thaumatin-like protein isoform 2), spot 22 (glutathione S-transferase) and spot 28 ( $\beta$-1,3-glucanase) to stress response and defense; spot 16 (cysteine protease) and spot 23 (papainlike cysteine proteinase) to senescence.

For the down-regulated ones, spot 8 (14-3-3 protein homologues), spot 10 (C2 domain) and spot 38 (small Ras-related GTP-binding protein) were related to signal transduction; spot 6 (adenosine kinase), spot 20 (transketolase), spot 30 (enolase) and spot 37 (isocitrate dehydrogenase (NADP+)) to metabolism; spot 18 (actin) and spot 27 (Actin depolymerisation factor/cofilin -like domains) to cell structure; spot 2 (plant basic secretory protein), spot 24 (class III peroxidases), spot 33 (dehydroascorbate reductase) and spot 34 (chitinase class I) to stress response and defense; spot 11 (glycine-rich RNA-binding protein), spot 13 (putative chaperonin 21 precursor), spot 15 (putative ribosomal protein $\mathrm{S} 12$ ) and spot 31 (RNA recognition motif) to protein synthesis; Furthermore, the functions of spot 9 (DREPP plasma membrane polypeptide), spot 29 (WD40 domain), spot 35 (LbH_gamma_CA_like) and spot 36 (ricinB_lectin_2) were still unclarified.

On the other hand, when compared to control tissue the responses of 29 proteins during storage were enhanced after fresh-cut operations. However, the expressions of spot 2, spot 6 , spot 10 , spot 24, spot 35 , and spot 38 , which decreased during storage of whole $Z$. latifolia, were up-regulated after fresh-cut operation, indicating that they might play vital roles in response to wounding stress.

\section{Discussion}

During senescence and quality deterioration of Z. latifolia, a variety of physiological and biochemical responses occurred, in association with the changes in the protein profile, which could be influenced by a variety of internal or external factors could impact such process. In this study, changes in abundance of 35 proteins between whole and fresh-cut $Z$. latifolia during storage were observed based on 2-fold difference. They are suggested to play roles in signal transduction, carbohydrate and nucleotide metabolism, cell structure, stress response and defense, protein synthesis, as well as senescence.

\section{Identified proteins related to signal transduction}

Signal transduction is the process which begins with the binding of specific ligands to receptors located at the surface of the plasma membrane, thus causing an intracellular metabolic change. ${ }^{17}$ Three proteins involved in signal transduction were identified, including 143-3-like protein (Os08g0430500, spot 8), C2 domains (Os08g0562600, spot 10) and small ras-related GTP-binding protein (spot 38). 14-3-3like proteins are important regulators of signal transduction pathways through binding to multiple functionally diverse signaling proteins such as kinases, phosphatases and transmembrane receptors. ${ }^{18,19} \mathrm{C} 2$ domains are usually $\mathrm{Ca} 2+$-dependent membrane-targeting module found in many cellular proteins, functions in membrane trafficking or signal transduction. ${ }^{20}$ As a signaling element, small ras-related GTP- 
binding proteins meditate various external stimuli to intracellular signaling pathways. ${ }^{21,22}$ All of them decreased during the storage of whole Z. latifolia; however, spot 10 and spot 38 were up-regulated by fresh-cut operation, suggesting that signal transduction was enhanced.

\section{Identified proteins related to metabolism}

Regulation of physiological metabolism is an important strategy for plant to adapt to (a) biotic stresses. ${ }^{23}$ Two protein involved in nucleotide metabolism were identified: adenosine kinase (AK, spot 6) which is involved in the purine salvage pathway plays a key role in the prevention of adenosine accumulation and support the metabolic cycling of adenosine, ${ }^{24}$ while diphosphonucleotide phosphatase 1 (DPP, spot 26) catalyzes the hydrolysis of a wide range of activated phosphoric acid mono- and di-esters and anhydrides at $\mathrm{pH}$ of 5-6. ${ }^{25} \mathrm{In}$ this study, the biosynthesis of AK and DPP increased after fresh-cut operation at $3 \mathrm{rd}$ and/or 5thdays of storage, indicating that nucleotide catabolism was enhanced.

Fructokinases (Os08g0113100) (FRKs, spot 14), glycosyl hydrolases family 17 SORBIDRAFT_09g018750) (GHF, spot 17), 2,3-bisphosphoglycerate-independent phosphoglycerate mutase (Os05g0482700) (BIPM, spot 19), transketolase (TK, spot 20), enolase (spot 30) and isocitrate dehydrogenase NADP+ (IDH, spot 37) play important roles in carbohydrate metabolism. ${ }^{26}$ Of these, GHF belong to the glycosyl hydrolase family and catalyzes the hydrolysis of polysaccharides to monosaccharides. ${ }^{27}$ Freshcut significantly increased the expression of GHF during storage, suggesting an enhanced carbohydrate catabolism. FRKs, BIPM and enolase are involved in Glycolysis ${ }^{28}$ IDH is the key enzyme in the tricarboxylicacidcycle acid (TCA) cycle, ${ }^{29}$ while TK is the key enzyme of the pentose phosphate pathway. ${ }^{30}$ Glycolysis, TCA cycle and pentose phosphate pathways provide energy and inter-conversion building blocks for metabolites synthesis. ${ }^{11,15}$ The higher expressions of these proteins after fresh-cut operation implied that the reduction of energy supplement.

\section{Identified proteins related to cell structure}

The plant cell wall is of great importance to provide shape to cells, form the interface between adjacent cells as well as resisting the invasion of pathogens. ${ }^{31}$ Three proteins related to cell structure were identified, including profilin (Os06g0152100, spot 1), actin (spot 18) and actin depolymerisation factor/cofilin -like domains (Os03g0780400) (ADF, spot 27). Actin is a ubiquitous protein involved in the formation of filaments, a major component of the cytoskeleton. ${ }^{29}$ Profilin may link the cytoskeleton with major signaling pathways by interacting with components of the phosphatidylinositol cycle and Ras pathway, which plays a central role in the assembly of branched actin filament networks. ${ }^{32}$ On the other hand, ADF, a family member of essential eukaryotic actin regulatory proteins, could enhance the turnover rate of actin and interact with actin monomers and actin filaments..$^{33}$ In comparison with those in control, the abundance of ADF was higher in fresh-cut Z. latifolia during storage while the biosynthesis of profilin and actin was down-regulated, suggesting that fresh-cut accelerated the cell structure disassembly, which was further validated by cell ultrastructural observation using transmission electron microscope (unpublished data).

\section{Identified proteins related to stress response and defense}

Stress response would cause alternation in composition of plant transcriptome, proteome and metabolome, which mediated via profound changes in gene expression..$^{34}$ Of the eleven stress response and defense proteins up-regulated by fresh-cut operation, eight were related to disease resistance. plant basic secretory protein (BSP, spot 2 ) is believed to be part of the plants defense mechanism against pathogens, ${ }^{35} \beta$-1,3-glucanase precursor (spot 3, 5), glucan endo1,3-beta-glucosidase (spot 4) and $\beta$-1,3-glucanase (spot 28) could degrade fungal cell wall polysaccharides, ${ }^{36}$ universal stress protein family (USP, spot 12) is a small cytoplasmic bacterial protein whose expression is enhanced when the cell is exposed to stress agents, ${ }^{13}$ thaumatin-like protein isoform 2 (TLP, spot 21) plays a roles in host defense and developmental processes, ${ }^{37}$ while chitinase class I (spot 34) catalyzes the hydrolysis of the beta-1,4-N-acetyl-D-glucosamine linkages in chitin polymers of fungal cell walls. ${ }^{38}$ The higher abundances of these proteins (except chitinase class I) in fresh-cut $Z$. latifolia when compared to those in control provide a good indication that fresh-cut operation induced elevation in anti-pathogen capability.

Senescence is a vital aspect of vegetable life cycles, and directly affects vegetable quality and resistance to pathogens. Reactive oxygen species (ROS), as the primary mediators of oxidative damage in plants, are involved in senescence. ${ }^{39}$ Furthermore, superoxide dismutase (SOD), ascorbate peroxidase (APX), dehydroascorbate reductase (DHAR), glutathione S-transferase (GST) and peroxidases (POD) are antioxidant enzymes related to ROS metabolism. ${ }^{40}$ In this study, three ROS metabolism related proteins identified were GST (spot 22), class III peroxidases (PODIII, spot 24) and DHAR (spot 33). GST is cytosolic dimeric proteins involved in cellular detoxification by catalyzing the conjugation of glutathione (GSH) with a wide range of endogenous and xenobiotic alkylating agents, ${ }^{12}$ while DHAR catalyzes the reduction of dehydroascorbate into ascorbic acid (AsA) using GSH as the reductant., ${ }^{40}$ Both GST and DHAR are involved in the ascorbate-glutathione cycle (Figure 7), which has been regarded as one of the most important antioxidant pathways for hydrogen peroxide (H2O2) detoxification. PODIII, located in the extracellular space or in the vacuole in plants, is involved in indole-3-acetic acid degradation, lignin biosynthesis, wound healing, general stress response and pathogen defense, and $\mathrm{H} 2 \mathrm{O} 2$ detoxification. ${ }^{29}$ In previous studies, we found that fresh-cut significantly $(\mathrm{p}<0.05)$ promoted the increase of POD activity in Z. latifolia during $25^{\circ} \mathrm{C}$ storage (unpublished date), which was validated by POD expression pattern in the present study. Based on these results, we speculated that ROS damage could be involved in senescence and quality deterioration of fresh-cut $Z$. latifolia.

\section{Identified proteins related to protein synthesis}

The regulation of protein synthesis plays a key role in the control of cell growth, proliferation, and apoptosis. ${ }^{41}$ In this study, four proteins identified are responsible for protein synthesis, glycine-rich RNAbinding protein (GRP, spot 11), putative chaperonin 21 precursor (C21P, spot 13), putative ribosomal protein S12 (RPS12, spot 15) and RNA recognition motif (RRM, spot 31) were identified. GRP suggested to play a role in responses to environmental stresses, ${ }^{42} \mathrm{C} 21 \mathrm{P}$ help nascent peptide chain precursor reconciliation folded protein peptide chain folds into a protein possessing a biological function, ${ }^{43}$ RPS12, located at the subunit interface, supposedly play critical roles in interacting with the tRNA substrates and the large subunit, ${ }^{44} \mathrm{RRM}$, a highly abundant domain of the proteins in eukaryotes, participates in post-transcriptional gene expression processes, including mRNA and rRNA processing, RNA export, and RNA stability. ${ }^{45}$ The biosynthesis of these proteins was down-regulated after fresh-cut, suggesting that fresh-cut operation weaken the protein assimilation of Z. latifolia. 


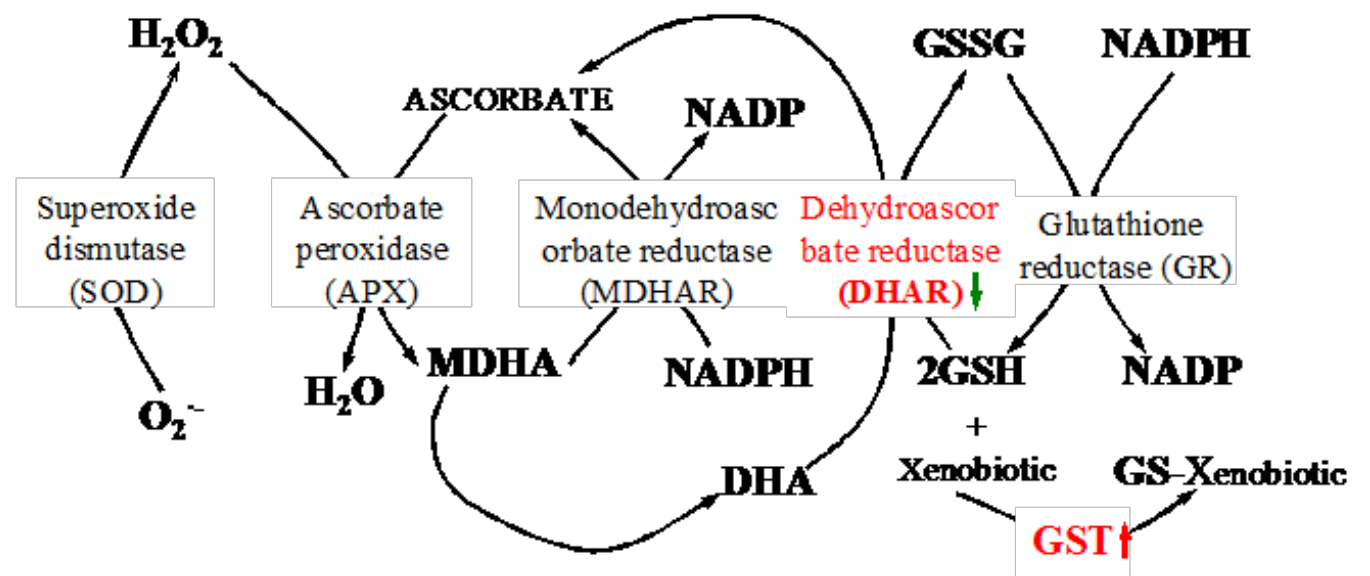

Figure 7 Changes in ascorbate-glutathione cycle after fresh-cut treatment.

\section{Identified proteins related to senescence}

Senescence caused by pathogens, environmental stresses, or inherent physiological changes is a collective term for the deteriorative changes in living organisms, leading to death. Two proteins, cysteine proteases (CPs, spot 16) and papain-like CPs (spot 23), were supposed to be related with the senescence. CPs are enzymes that degrade proteins by cleave the peptide bond, and participated in a wide range of physiology and development processes. ${ }^{46}$ In this study, CPs (spot 16) and papain-like CPs (spot 23) significantly up-regulated after fresh-cut operation during storage. It is likely that the wounding stress caused by fresh-cut enhanced the protein catabolism, which may play a major role in senescence and quality deterioration of $Z$. latifolia.

\section{The unclear functional proteins}

Four spots identified as DREPP plasma membrane polypeptide (spot 9), WD40 domain (spot 29), LbH_gamma_CA_like (spot 35) and RicinB_lectin_2 (spot 36). Although they were searched by BLASTP matches of the corresponding protein accessions, their functions were still unclear. The expressions of spot 9, 29, and 36 showed similar expression pattern in both whole and fresh-cut $Z$. latifolia during storage; nevertheless, LbH_gamma_CA like (spot 35), which decreased in whole stem, showed an opposite trend in fresh-cut tissue during storage. These results suggested that $\mathrm{LbH}_{-}$ gamma_CA_like might play directly/indirectly role in response to wounding stress.

\section{Conclusion}

This study demonstrated that when compared to integral stem the dynamic proteome changes of 35 proteins identified were significantly altered after fresh-cut operation in association with the accelerated senescence and quality deterioration. Based on their functions, the possible mechanisms of fresh-cut operation accelerating senescence and quality deterioration of Z. latifolia might be due to: (1) enhancement of production and transduction of wounding signals; (2) enhancement of the carbohydrate, nucleotide and protein catabolism, but attenuation of the protein assimilation, glycolysis, TCA cycle and pentose phosphate pathways, thus reducing the energy supplement; (3) inducement of the expression of pathogenesis-related proteins and antioxidant enzymes; (4) acceleration of the cell structure disassembly. This study has put forward interpretable data and provided new perspectives on the mechanism of fresh-cut operations accelerating senescence and quality deterioration of $Z$. latifolia. However, further detailed investigation of these proteins' specific roles and their functional correlation with wounding response should be performed to better understand the mechanism of fresh-cut operations accelerate senescence and quality deterioration.

\section{Acknowledgements}

This work was supported by the National Natural Science Foundation of China (31401612), the Natural Science Foundation of Zhejiang Province of China (LY14C200005), and the Zhejiang Open Foundation of the Most Important Subjects (KF2012006).

\section{Conflict of interest}

The author declares no conflict of interest.

\section{References}

1. Fan X, Ren X, Liu Y, et al. Genetic structure of wild rice Zizania latifolia and the implications for its management in the Sanjiang Plain, Northeast China. Biochem Syst Ecol. 2016;64:81-88

2. Han S, Zhang H, Zhai C. Protective potentials of wild rice (Zizania latifolia (Griseb) Turcz) against obesity and lipotoxicity induced by a high-fat/cholesterol diet in rats. Food Chem Toxicol. 2012;50(7):22632269.

3. Choi JH, Suzuki T, Kawaguchi T, et al. Makomotines A to D from Makomotake, Zizania latifolia infected with Ustilago esculenta. Tetrahedron Lett. 2014;55(26):3596-3599.

4. Yan $\mathrm{N}$, Wang $\mathrm{X}, \mathrm{Xu} \mathrm{X}$, et al. Plant growth and photosynthetic performance of Zizania latifolia are altered by endophytic Ustilago esculenta infection. Physiol Mol Plant P. 2013;83:75-83.

5. Cao L, Liu M, Zhang H. Sanitizers affect chemical compositions and physical characteristics of few-flower wildrices under modified atmosphere packaging. Philipp Agric Sci. 2010;93(4):446-453.

6. Luo H, Jiang L, Zhang L, et al. Quality changes of whole and freshcut Zizania latifolia during refrigerated $\left(1{ }^{\circ} \mathrm{C}\right)$ storage. Food Bioprocess Tech. 2012;5(4):1411-1415.

7. Liu M, Qian B, Zhang H, et al. Sanitizer treatments alleviate lignification of sliced few-flower wildrice (Zizania latifolia Turcz). Food Res Int. 2010;43(10):2363-2368.

8. Fang X, Gao H, Song L, et al. Hypobaric storage maintains postharvest quality and regulates cell wall metabolism in water bamboo shoot. Transactions of the CASE. 2013;29(12):257-263.

9. Zhou J, Luo H, Wang J, et al. Effect of nano-chitosan coating on quality of fresh-cut Zizania latifolia. Modern Food Sci Technol. 2013;29:18831887. 
10. Laštovičková M, Bobálová J. MS based proteomic approaches for analysis of barley malt. J Cereal Sci. 2012;56(3):519-530.

11. Ray D, Ye P. Characterization of the metabolic requirements in yeast meiosis. PloS One. 2013;8(5):e63707.

12. López-Vidal O, Camejo D, Rivera-Cabrera F, et al. Mitochondrial ascorbate-glutathione cycle and proteomic analysis of carbonylated proteins during tomato (Solanum lycopersicum) fruit ripening. Food Chem. 2016;194:1064-1072.

13. Luo H, Jiang L, Bao Y, et al. Changes of protein profile in Zizania latifolia during cooling storage. Trans Chinese Soc Agric Eng. 2014;30:285-292.

14. Luo H, Bao Y, Jiang J, et al. Proteome changes of fresh-cut Zizania latifolia during refrigerated $\left(1^{\circ} \mathrm{C}\right)$ storage. Eur Food Res Technol. 2012;235(6):1011-1021.

15. Huang J, Zhang Y, Jiang L, et al. Comparative proteomics analysis of differential proteins in response to 6-benzylaminopurine treatment in Pteridium aquilinum senescence. Postharvest Biol Tec. 2016;116:66-74.

16. Mithoe SC, Menke FLH. Phosphoproteomics perspective on plan signal transduction and tyrosine phosphorylation. Phytochemistry. 2011;72(10):997-1006.

17. Jiang L, Kang R, Zhang L, et al. Differential protein profiles of postharvest Gynura bicolor DC leaf treated by 1-methylcyclopropene and ethephon. Food Chem. 2015;176:27-39.

18. Hopff D, Wienkoop S, Lüthje S. The plasma membrane proteome of maize roots grown underlow and high iron conditions. J Proteomics. 2013;91:605-618.

19. Swigonska S, Weidner S. Proteomic analysis of response to long-term continuous stress in roots of germinating soybean seeds. J Plant Physiol. $2013 ; 170(5): 470-479$

20. Antal CE, Callender JA, Kornev AP, et al. Intramolecular C2 domainmediated autoinhibition of protein kinase CbII. Cell Rep. 2015;12:12521260 .

21. Hurkman WJ, Vensel WH, Tanaka CK, et al. Effect of high temperature on albumin and globulin accumulation in the endosperm proteome of the developing wheat grain. J Cereal Sci. 2009;49(1):12-23.

22. Zhang H, Liu T, Zhang Z, et al. Integrated proteogenomic characterization of human high-grade serous ovarian cancer. Cell. 2016;166(3):755-765.

23. Khraiwesh B, Zhu JK, Zhu J. Role of miRNAs and siRNAs in biotic and abiotic stress responses of plants. BBA-Gene Regul Mech 2012;1819(2):137-148.

24. Jiang J, Jiang L, Zhang L, et al. Changes of protein profile in freshcut lotus tuber before and after browning. J Agric Food Chem. 2012;60(15):3955-3965.

25. Olczak M, Ciuraszkiewicz J, Wójtowicz H, et al. Diphosphonucleotide phosphatase/phosphodiesterase (PPD1) from yellow lupin (Lupinus luteus L) contains an iron-manganese center. FEBS Lett. 2009;583(19):32803284 .

26. Berg J, Tymoczko J, Stryer L. Biochemistry. 5th ed. USA: W H Freeman and Company; 2002.

27. Bazargani MM, Sarhadi E, Bushehri AAS, et al. A proteomics view on the role of drought-induced senescence and oxidative stress defense in enhanced stem reserves remobilization in wheat. J Proteomics. 2011;74(10):1959-1973.

28. Turner JF, Turner DH. The regulation of glycolysis and the pentose phosphate pathway. Biochem Plants. 2014;2:279-316.
29. Kong F-J, Oyanagi A, Komatsu S. Cell wall proteome of wheat roots under flooding stress using gel-based and LC MS/MS-based proteomics approaches. Biochim Biophys Acta. 2010;1804(1):124-136.

30. Yin X, Sakata K, Nanjo Y, et al. Analysis of initial changes in the proteins of soybean root tip under flooding stress using gel-free and gel-based proteomic techniques. J Proteomics. 2014;106:1-16.

31. Albersheim P, Darvill A, Roberts K, et al. Plant Cell Walls. USA: Garland Science; 2010

32. Didry D, Carlier MF, Pantaloni D. Synergy between actin depolymerizing factor/cofilin and profilin in increasing actin filament turnover. $J$ Bio Chem. 1998;273(40):25602-25611.

33. Allwood EG, Smertenko AP, Hussey PJ. Phosphorylation of plant actindepolymerising factor by calmodulin-like domain protein kinase. Febs Lett. 2001;499(1-2):97-100.

34. Pérez-Clemente RM, Vives V, Zandalinas SI, et al. Biotechnological approaches to study plant responses to stress. BioMed Res Int. 2013;1:110

35. Devnath S, Kataoka T, Miura K, et al. Cgr11 encodes a secretory protein involved in cell adhesion. Eur J Cell Biol. 2009;88(9):521-529.

36. Finnie C, Bak-Jensen KS, Laugesen S, et al. Differential appearance of isoforms and cultivar variation in protein temporal profiles revealed in the maturing barley grain proteome. Plant Sci. 2006;170(4):808-821.

37. Xu C, Sullivan JH, Garrett WM, et al. Impact of solar Ultraviolet-B on the proteome in soybean lines differing in flavonoid contents. Phytochemistry. 2008;69(1):38-48.

38. Wang LY, Wang YS, Cheng H, et al. Cloning of the Aegiceras corniculatum class I chitinase gene (AcCHI I) and the response of AcCHI I mRNA expression to cadmium stress. Ecotoxicology. 2015;24(7-8):1705-1713.

39. Posmyk MM, Kontek R, Janas KM. Antioxidant enzymes activity and phenolic compounds content in red cabbage seedlings exposed to copper stress. Ecotox Environ Safe. 2009;2(2):596-602.

40. Zhang YJ, Wang W, Yang HL, et al. Molecular properties and functional divergence of the dehydroascorbate reductase gene family in lower and higher plants. PloS one. 2015;10(12):e0145038.

41. Thompson JE, Hopkins MT, Taylor C, et al. Regulation of senescence by eukaryotic translation initiation factor 5A:implications for plant growth and development. Trends Plant Sci. 2004;9(4):174-179.

42. Ciuzan O, Hancock J, Pamfil D, et al. The evolutionarily conserved multifunctional glycine-rich RNA-binding proteins play key roles in development and stress adaptation. Physiol Plant. 2015;153(1):1-11.

43. Wen F, Zhang Z, Bai T, et al. Proteomics reveals the effects of gibberellic acid (GA3) on salt-stressed rice (Oryza sativa L) shoots. Plant Sci. 2010;178(2):170-175

44. Aphasizheva I, Maslov DA, Aphasizhev R. Kinetoplast DNA-encoded ribosomal protein S12:a possible functional link between mitochondrial RNA editing and translation in Trypanosoma brucei. RNA Biol. 2013;10(11):1679-1688.

45. Toba G, White K. The third RNA recognition motif of Drosophila ELAV protein has a role in multimerization. Nucleic Acids Res. 2008;36(4):1390-1399.

46. Roberts IN, Caputo C, Criado MV, et al. Senescence-associated proteases in plants. Physiol Plant. 2012;145(1):130-139. 